Original Research Paper

\title{
Factors Causing Deaths Due to Injury among Children in Bangladesh
}

\author{
${ }^{1}$ Md Hasinur Rahaman Khan, ${ }^{2}$ Tahera Ahmed and ${ }^{3,4}$ Faisal Ababneh \\ 1,2 Applied Statistics, Institute of Statistical Research and Training, University of Dhaka, Dhaka 1000, Bangladesh \\ ${ }^{3}$ Department of Mathematics and Statistics, Sultan Qaboos University, Oman \\ ${ }^{4}$ Department of Mathematics, Al-Hussein Bin Talal University, Maan, Jordan
}

Article history

Received: 19-06-2015

Revised: 08-09-2015

Accepted: 14-09-2015

Corresponding Author: Md Hasinur Rahaman Khan Applied Statistics, Institute of Statistical Research and Training, University of Dhaka, Dhaka 1000, Bangladesh Email: hasinur@isrt.ac.bd

\begin{abstract}
Bangladesh experiences high infant and child mortality for many years, for which child injury appears to be one of the most important modes of mortality. We modelled "death due to injury" using a logistic regression to study the differentials of death due to accidental injuries fall, drowning, road accident, burn, poisoning, animal bite, cut according to different socioeconomic characteristics using Bangladesh Health and Injury Survey data. The analysis revealed that children in rural areas got injury and then died very frequently by different accidents, most of the children died from drowning, the death rate of children who were injured was highest at home and mother's education status was also an important factor for child injury and death. The uneducated mothers were not aware of the effect of injuries of their children that caused death. In most cases lack of adequate supervision carelessness turned out to be causes these accidental deaths.
\end{abstract}

Keywords: Child Health, Child Survival, Child Injury, Logistic Regression, Modelling Child Injury

\section{Introduction}

Today's child is tomorrow's future. A nation that ignores its children is a nation without a future. According to BBS (2005), in 2001 total population of Bangladesh was 131, 269, 860 and among them almost half (47\%) of the population were children and all of our future. Every child after his/her birth must get rights to fulfil every basic needs, safety and facilities on this earth. But if any study looks a little bit deeper we can visualize a very sad but true picture that children don't get their proper rights and also face different kinds of problems.

In recent times, many developing countries including Bangladesh, not only have to cope with infectious diseases and malnutrition but also with new health problems such as injuries and that has been identified as a leading cause of both morbidity and mortality for children. Generally injury is any harm or damage or hurt done to a person or a part of his/her body caused unintentionally. Child injury refers to the injury of the body of child due to accident or violence. According to World Health Organization (Krug, 1999) child injury has serious, physical consequences which adversely affect health; it refers to any act which endangers his or her optimum health, survival and development". After the infancy the main leading cause of child death is injury. Generally children from birth until 18 years are highly susceptible to all types of injury (Rahman et al., 2005).

Child injury has become a public health issue in both developed and developing countries. World Health Organization (Peden et al., 2008) reported almost 6 million children die all over the world due to injury. Injuries are categorized into unintentional (accidental) and intentional (deliberate). Here our main concern is to discuss about accidental child injuries. Road accidents, drowning, burns, falls, accidental poisoning, animal bites, machine injury, electric shocks etc. are the different types of injury. These all affect children and as a result sometimes death occurs. In this study, major differences in frequency of injuries between urban and rural residents would observed, perhaps because of the hazards of agricultural machinery, chemicals and exposed bodies of water (Chowdhury et al., 2009). The evidence from the 2000 Demographic Surveillance System (HDSS, 2000) of the International Centre for Diarrhoeal Dis-ease Research, Bangladesh (ICDDR, B), shows a growing proportion of child deaths due to injuries. In Bangladesh, there are only few studies (Aditya et al., 1989; Rahman et al., 1998) that show the burden of injuries. However, most of the child health programs in Bangladesh are focused on prevention of infectious and nutritional causes of child death. 
In 2003 the Vietnam Multi-Center Injury Survey (Linnan et al., 2003) revealed a study with the help of UNICEF to understand the picture of under 18 children drowning in An-giang and NinhThuan and also identified risks, causes and recommendations of suitable preventive measures by using cross sectional retrospective methodology. An organization SAFE KIDS worldwide undertook a study in 2002 (Taft et al., 2002) where it was found that more than a million children aged 14 and under die each year from unintentional injuries. In 1990, injuries in the developing countries contributed to $13 \%$ of total disability adjusted life years among children. It is expected that by 2020 , this share will increase to $22 \%$ (Deen et al., 1999). Traffic crashes, drowning, poison, falls and other risks are main leading causes of death to children worldwide. Ac-cording to some of the past studies (e.g., Rahman et al., 2005) three children die every hour from injuries, two children suffer serious but non-fatal injuries every minute leading to over 13,000 permanent disabilities. This study aims to determine the factors related to the deaths due to injury under18 children for both rural and urban areas in Bangladesh using the 2005 BHIS data and to recommend the possible preventive measures. Children also suffer from keloid disease. The mathematical modelling of the keloid disease triggered by a virus has been recently investigated by Bianca and Fermo (2011), where it was shown that the kinetic type of model is able to depict the emerging behaviours which occur during the keloid formation and to investigate the model that is related to the bifurcation analysis of the measurable macroscopic variables associated to each functional subsystem.

\section{Data and Variables}

The 2005 Bangladesh Health and Injury Survey is the largest injury survey ever conducted at the community level in a developing country, with a sample size of 171,366 households and a total surveyed population of 819,429 . The survey, conducted between January and December of 2003, included all age groups; 43 percent $(351,651)$ of the surveyed population were children. The 2005 BHIS survey was based on a multistage cluster sampling where out of total 171,366 households, 88,380 collected from rural areas, 45,183 from district towns (urban areas) and 37,803 households from Dhaka metropolitan city. Twelve out of 64 districts were randomly selected for the survey. A separate survey of Dhaka metropolitan city was included to show the injury picture of a large metropolitan mega-city environment. This sample was included in the national data for the overall analysis.

In the survey mothers of the children were preferred as the main respondent. When a mother was unavailable, the most knowledgeable member of the household present at the time of interview was the respondent. The dependent variable used in the study is "death due to injury" among the children whose age ranges from 0 to 17 because they are the victim of different types of injuries and injury is one of the main causes of child death. We consider a large number of explanatory variables that are potentially associated with children death due to injury such as injury mechanism, religion, gender, care sought during illness, father's education status, mother's education status, electricity connection, place of residence, place of death.

\section{Method}

We describe the child death cause for injury and its relationship with the potential variables as stated in previous section using simple association test. We then implement the binary logistic regression model to the children's death due to injury data for a set independent variable. The statistical relationship between the dependent and potential independent variables is investigated with $x^{2}$ test statistic.

There are many statistical techniques for modelling dichotomous dependent variables, of which the binary logistic regression (Hosmer and Lemeshow, 1989) is the widely used model. The model is usually used to identify risk factors along with predicting the probability of 'success' $\left(p_{i}\right)$ or in turn the probability of 'failure' $\left(1-p_{i}\right)$. Under the model, the logistic pattern can easily be interpreted in terms of odds ratio where relative odds can be estimated for the categories of each categorical independent variables or combination of such variables.

Suppose we have a collection of $p$ independent variables denoted by $X=\left(X_{i 1}, X_{i 2, \ldots \ldots, X_{i p}}\right) ; i=1,2, \ldots \ldots, n$ and $y$ be the dichotomous dependent variable takes values 0 and 1 . Now define:

$$
\begin{aligned}
& \pi\left(X_{i}=x_{i}\right)=p\left(y_{i}=1 \mid X=x\right) \\
& =\frac{\exp \left(\beta_{0}+\beta_{1} x_{i 1}+\beta_{2} x_{i 2}+\ldots \ldots \ldots+\beta_{p} x_{i p}\right)}{1+\exp \left(\beta_{0}+\beta_{1} x_{i 1}+\beta_{2} x_{i 2}+\ldots \ldots \ldots .+\beta_{p} x_{i p}\right)}
\end{aligned}
$$

And similarly $1-\pi\left(x_{i}\right)$. Then the logit transformation is defined by:

$$
\begin{aligned}
& g\left(x_{i}\right)=\log i t\left[\pi\left(x_{i}\right)\right]=\ln \left[\frac{\pi\left(x_{i}\right)}{1-\pi\left(x_{i}\right)}\right] \\
& =\left(\beta_{0}+\beta_{1} x_{i 1}+\beta_{2} x_{i 2}+\ldots \ldots \ldots . .+\beta_{p} x_{i p}\right)
\end{aligned}
$$

The importance of logit transformation is that $g\left(x_{i}\right)$ has many of the desirable properties of a linear regression model. The logit $g\left(x_{i}\right)$ is linear in its parameter, may be continuous and may range from $-\infty$ to $+\infty$, depending on the range of $X$ and can be solved 
using the maximum likelihood estimation technique. For testing the overall significance of the coefficients of all the parameters in the model we use the likelihood ratio statistic (say, $D$ ) which has the form:

$$
D=-2 \sum_{i=1}^{n}\left[y_{i} \ln \frac{\hat{\pi}\left(x_{i}\right)}{y_{i}}+(1-y) \ln \frac{1-\hat{\pi}\left(x_{i}\right)}{1-y_{i}}\right]
$$

Here $D$ is approximately distributed as $x^{2}$ with $p$ degree of freedom. The parameters are tested using the Wald test statistics that is defined as $\frac{\hat{\beta}_{i}}{\text { S.E. }\left(\hat{\beta}_{i}\right)}$, where $\hat{\beta}_{i}$ is the maximum likelihood estimate and S.E. $\left(\hat{\beta}_{i}\right)$ is the standard error. The results of the model can be interpreted mostly with the odds ratio. The odds ratio is a measure of association that approximates how much more likely (or unlikely) it is for the outcome to present among those with, for any particular independent variable, $X=1$ than among those with $X$ $=0$. An odds is the ratio of the probability that the event will occur over the probability that the same event will not occur i.e. $\frac{\pi(x)}{1-\pi(x)}$.

\section{Data Analysis}

Since the bivariate analysis can be helpful in testing simple hypotheses of association and causality checking to what extent it becomes easier to know and predict a value for the dependent variable if we know a case's value of the independent variable, we have carried out the bivariate analysis for explaining the differential of children who died due to injury influenced by different factors. The results are shown in Table 1.

Table 1 shows the background information particularly, the percentage of child death due to injury in influenced by different factors. The rate of child death from drowning is the highest $(25.98 \%)$ and the lowest from electricity or lightening (3.65\%). The summary results also can be seen in Fig. 1. The child death due to injury is the highest among Muslim (88\%) and the lowest among Buddhist $(0.25 \%)$. Male children died more due to injury $(55.9 \%)$. The child death is found as the highest when there is no care during illness $(50.32 \%)$. In case of illiterate fathers child death rate is the highest $(58.43 \%)$ and it is the lowest among those fathers who are graduate (1\%). The rate of child death due to injury is the highest for illiterate mothers $(54.03 \%)$. Almost $48.81 \%$ children get injured and die with the facility of having electricity in their homes. In rural area child death is the highest $(62.87 \%)$ and the lowest in urban area $(37.14 \%)$. The death rate of children is the highest at home $(46.26 \%)$ and the lowest at health care centre $(6.84 \%)$.
Table 1. Differential of child death due to injury according to different characteristic of factors

\begin{tabular}{|c|c|c|c|}
\hline \multirow[b]{2}{*}{ Variables } & \multicolumn{2}{|c|}{ Death due to injury } & \multirow[b]{2}{*}{ Total $(\%)$} \\
\hline & Yes $(\%)$ & No $(\%)$ & \\
\hline \multicolumn{4}{|l|}{ Injury mechanism* } \\
\hline Traffic injury & 20.98 & 12.50 & 20.71 \\
\hline Assault & 7.98 & 0.00 & 7.93 \\
\hline Fall/hit by falling objects & 16.91 & 29.20 & 17.30 \\
\hline Drowning & 25.98 & 4.20 & 25.29 \\
\hline Hot object/smoke & 5.14 & 8.30 & 5.24 \\
\hline Electricity/lightening & 3.63 & 4.20 & 3.67 \\
\hline Animal bite & 4.74 & 12.50 & 4.98 \\
\hline Hanging & 4.19 & 4.20 & 4.20 \\
\hline Others & 10.41 & 25.00 & 10.88 \\
\hline \multicolumn{4}{|l|}{ Religion } \\
\hline Muslim & 88.00 & 86.90 & 87.08 \\
\hline Hindu & 11.18 & 12.47 & 12.35 \\
\hline Christian & 0.49 & 0.29 & 0.25 \\
\hline Buddho & 0.25 & 0.32 & 0.31 \\
\hline \multicolumn{4}{|l|}{ Gender } \\
\hline Male & 55.99 & 55.81 & 55.75 \\
\hline Female & 44.30 & 44.20 & 44.25 \\
\hline \multicolumn{4}{|l|}{ Care sought during illness* } \\
\hline Yes & 49.68 & 79.00 & 75.47 \\
\hline No & 50.32 & 20.90 & 24.53 \\
\hline \multicolumn{4}{|l|}{ Father's education status } \\
\hline Illiterate & 58.43 & 56.57 & 56.81 \\
\hline Primary & 24.40 & 25.38 & 25.25 \\
\hline Secondary & 15.36 & 15.55 & 15.52 \\
\hline Higher secondary & 1.03 & 1.47 & 1.40 \\
\hline Graduate & 1.00 & 1.02 & 1.01 \\
\hline \multicolumn{4}{|l|}{ Mother's education status* } \\
\hline Illiterate & 54.03 & 54.51 & 6.86 \\
\hline Primary & 16.77 & 23.48 & 22.68 \\
\hline Secondary & 23.60 & 16.75 & 18.80 \\
\hline Higher Secondary & 0.93 & 2.21 & 2.05 \\
\hline Graduate & 4.65 & 3.02 & 1.01 \\
\hline \multicolumn{4}{|l|}{ Electricity connection* } \\
\hline Yes & 48.81 & 53.43 & 39.97 \\
\hline No & 51.18 & 46.56 & 47.01 \\
\hline \multicolumn{4}{|l|}{ Place of residence** } \\
\hline Urban & 37.41 & 40.27 & 39.97 \\
\hline Rural & 62.87 & 59.00 & 60.02 \\
\hline \multicolumn{4}{|l|}{ Place of death* } \\
\hline Hospital & 19.02 & 13.89 & 14.38 \\
\hline Heath care centre & 1.11 & 0.97 & 0.98 \\
\hline On the way of hospital or home & e 6.84 & 2.27 & 2.71 \\
\hline At home & 46.26 & 81.53 & 78.12 \\
\hline Others & 26.44 & 1.33 & 3.78 \\
\hline
\end{tabular}

The Table 1 also depicts clearly the strong association between death due to injury and the variables injury mechanism, care sought during illness, mother's education status, electricity connection, place of residence and place of death. Most strikingly father's education has not found statistically significant with the child death due to injury, although mother's education is found very strongly associated with death due to injury. Other important factors such as, gender and religion are not associated at all with death due to injury.

For fitting binary logistic regression model we consider only those variables that are found significant in the initial screening where bivariate analysis was done. 
Before fitting such model the dependent variable death due to injury was coded as:

$$
y=\left\{\begin{array}{l}
1, \text { if child is injured and died } \\
0, \text { otherwise }
\end{array}\right.
$$

The results are summarized in Table 2 which shows that the odds of dyeing among the children who died from hit or falling object animal bite and other injuries respectively 66,71 and $75 \%$ lower than the odds of dyeing from traffic injury. It is found that the odds of dyeing from drowning are 3.7 times more likely than the traffic injury. The odds ratio of no care sought during illness is found 3.8. Thus the odds of dyeing among the children for no care sought during illness is 3.8 times higher than the odds of dyeing for the care sought during illness. We also found that for mothers who have primary and higher secondary education their children got injured and then died have respectively $28 \%$ and $57 \%$ lower risk than that for the children of the illiterate mothers. On the other hand, both secondary and graduate educated mother's children died respectively 1.4 and 1.6 times more likely than that by the illiterate mother's children.

The odd of dyeing among the children due to not having electricity connection at home is 1.2 times higher than the odd of dyeing among children who have electricity connection. The rural children died from injury are 1.4 times more likely than the urban children. For place of death variable we consider "at hospital" as the reference category. The odds ratios of the places of death on the way of hospital or home, at home and other places are found as 2.915, 0.414 and 14.671 respectively. Hence the odd of dyeing among children who got injured and who were on the way of hospital is 2.9 times higher and among children who got injured and who were staying at home or other places is 14.7 times higher both than the odd of dyeing among children who went to hospital after injury. On the other hand, children died at home have $59 \%$ lower risk than the hospital.

Table 2. Logistic regression analysis results of children's death due to injury on its determinants

\begin{tabular}{|c|c|c|c|c|}
\hline Variable & Estimates & S.E. & p-value & Odds ratio \\
\hline \multicolumn{5}{|l|}{ Injury mechanism } \\
\hline Traffic injury (RC) & & & & 1.000 \\
\hline Assault & 8.2580 & 5.2333 & 0.997 & 6.770 \\
\hline Fall/hit by falling object & -1.0620 & 0.7000 & 0.012 & 0.346 \\
\hline Drowning & 1.3130 & 1.1600 & 0.025 & 3.716 \\
\hline Hot object /smoke & 1.0000 & 0.9310 & 0.282 & 0.368 \\
\hline Electricity or lightening & -0.6490 & 1.1730 & 0.580 & 0.523 \\
\hline Animal bite & -1.4880 & 0.8380 & 0.076 & 0.226 \\
\hline Hanging & -0.5110 & 1.7170 & 0.663 & 0.600 \\
\hline Others & -1.3930 & 0.7210 & 0.053 & 0.248 \\
\hline \multicolumn{5}{|l|}{ Care sought during illness } \\
\hline Yes (RC) & & & & 1.000 \\
\hline No & 1.3450 & 0.1250 & 0.000 & 3.825 \\
\hline \multicolumn{5}{|l|}{ Mother's education status } \\
\hline Illiterate (RC) & & & & 1.000 \\
\hline Primary & -0.3280 & 0.1640 & 0.042 & 0.720 \\
\hline Secondary & 0.3510 & 0.1500 & 0.019 & 1.421 \\
\hline Higher secondary & -0.8560 & 0.6000 & 0.015 & 0.425 \\
\hline Graduate & 0.7400 & 0.2970 & 0.038 & 1.555 \\
\hline \multicolumn{5}{|l|}{ Electricity connection } \\
\hline Yes (RC) & & & & 1.000 \\
\hline No & -0.1850 & 0.0740 & 0.013 & 1.203 \\
\hline \multicolumn{5}{|l|}{ Place of residence } \\
\hline Urban (RC) & & & & 1.000 \\
\hline Rural & 0.1320 & 0.0770 & 0.081 & 1.141 \\
\hline \multicolumn{5}{|l|}{ Place of death } \\
\hline At hospital (RC) & & & & 1.000 \\
\hline Other health care centre & -0.1730 & 0.3640 & 0.635 & 0.841 \\
\hline On the way of hospital or home & 0.7880 & 0.1780 & 0.000 & 2.913 \\
\hline At home & -0.8810 & 0.1020 & 0.000 & 0.414 \\
\hline Other & 2.6860 & 0.1490 & 0.000 & 14.671 \\
\hline
\end{tabular}




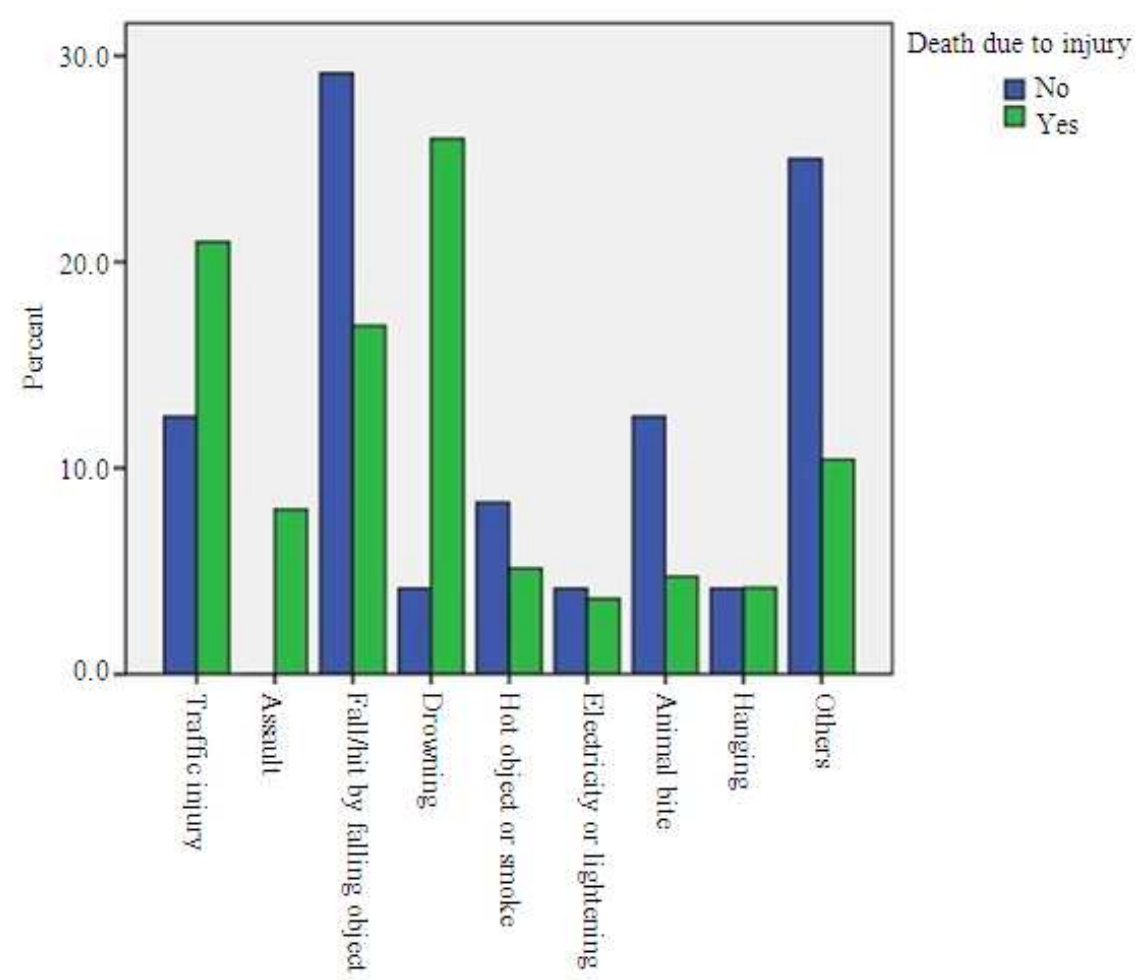

Fig. 1. Bar diagram of death due to injury and injury mechanism

\section{Discussion}

An attempt has been made to explore important factors that are associated with the under 18 children's injury to death in Bangladesh using the 2005 Bangladesh Health and Injury Survey data. The overall analysis shows that drowning is the leading killer of children in Bangladesh. Approximately 26\% children die from drowning in each year. The death from drowning is 3.7 times more likely than the traffic injury. Care is shown as an important factor to reduce the severity of child death due to injury. Almost $50 \%$ children die yearly when there is no care after getting injured. The children died for no care sought during illness is 3.8 times more likely to the care sought during illness. Mother's education unlike the father's education has a significant influence on child injury and death. It has been found that uneducated mothers are not so much conscious about the dangerous effect of injuries of their children. As a result the proportion of child death due to injury is the highest in case of mother's unconsciousness (54\%). Contrast results are also observed. The odds of dying due to child injury among secondary and graduate educated mother's children are respectively 1.4 and 1.6 times more than the odds of dying among illiterate mother's children. This may be due to the reason that educated mothers can find lower amount of time to look after their children because of being involved in job. We have also found that, almost $63 \%$ children get injured and died in rural areas and the death rate of children who were injured is the highest at home (46\%).

\section{Conclusion}

As injury is one of the leading causes of child death in Bangladesh, we have an opportunity to reduce injury and number of death by awareness of people. The family member should be careful about his/her children. As we get from the study that the highest number of children get injured and died at home so, a 'safe home program' is clearly essential in order to render homes less dangerous for children. The health system as a whole should be strengthened to provide high quality care to injured children, as well as rehabilitation and support services are needed. We have to make people aware about different modes of injuries that are causes of death and in this case mass media can play an important role to make them conscious. The government of Bangladesh should prepare a child injury prevention and control policy bringing in a wide range of sectors that may include transport, health, planning, consumer product safety, agriculture, education and law. There should also be representation across the disciplines, with child development experts, injury epidemiologists, engineers, urban planners, clinicians, social scientists and all other stockholders. Proper guidance and supervision of 
children is essential for the prevention of injury. Child labour should be stopped. However, accident injury prevention needs to be integrated into programmatic infrastructure of child survival and hence set for reducing child disability, mortality.

\section{Acknowledgement}

We are grateful to the Institute of Statistical Research and Training, University of Dhaka for providing technical support for this research.

\section{Funding Information}

The authors have no support or funding to report.

\section{Author's Contributions}

Md Hasinur Rahaman Khan: The author designed and coordinated the data analysis and contributed to the writing of the manuscript.

Tahera Ahmed: The author implemented the design, analysed the data and also contributed to the writing of the manuscript.

Faisal Ababneh: The author contributed to the analysis and the writing of the manuscript.

\section{Ethics}

This article is original and contains unpublished material. The corresponding author confirms that all of the other authors have read and approved the manuscript and no ethical issues involved.

\section{References}

Aditya, S.W., 1989. Trauma cases in a district hospital. J. Bangladesh Orthopaedic Society, 4: 34-40.

BBS, 2005. The Statistical Year Book, Bangladesh Bureau of Statistics, Dhaka.

Bianca, C. and L. Fermo, 2011. Bifurcation diagrams for the moments of a kinetic type model of keloidimmune system competition. Comput. Math. Appli., 61: 277-288. DOI: 10.1016/j.camwa.2010.11.003

Chowdhury, S.M., A. Rahman, S.R. Mashreky, M.S. Giash Uddin and L. Svanstrom et al., 2009. The Horizon of Unintentional Injuries among children in low-income setting: An Overview from Bangladesh health and injury survey. J. Environ. Public Health, 2009: 1-6. DOI: 10.1155/2009/435403
Hosmer, D.W. and S. Lemeshow, 1989. Applied Logistic Regression. 1st Edn., Wiley, New York, ISBN-10: 0471615536, pp: 307.

Deen, J.L., T. Vos, S.R. Huttly and J. Tulloch, 1999. Injuries and non-communicable diseases: Emerging health problems of children in developing countries. Bull. World Health Organization, 77: 518-524. PMID: 10427938

HDSS, 2000, Matlab, registration of health and demographic events. Health and Demographic Surveillance System, Centre for Health and Population Research.

Krug, E., 1999. Injury: A leading cause of the global burden of disease. World Health Organization, Geneva.

Linnan, M.J., C.V. Pham, C.L. Le, P.N. Le and A.V. Le, 2003. Report to UNICEF on the Vietnam multicenter injury survey. Hanoi School of Public Health, Center for Injury Policy and Prevention Research, Hanoi.

Peden, M., K. Oyegbite, J. Ozanne-Smith, A.A. Hyder and C. Branche et al., 2008. World report on child injury prevention. WHO, UNICEF.

Rahman, F., R. Andersson and L. Svanstrom, 1998. Health impact of injuries: A population-based epidemiological investigation in a local community of Bangladesh. J. Safety Res., 29: 213-222. DOI: $10.1016 / \mathrm{S} 0022-4375(98) 00048-6$

Rahman, A., A. Hannan and I. Uhaa, 2005. Bangladesh health and injury survey, report on children. Ministry of Health and Family Welfare of Bangladesh, ICMH, UNICEF, TASC, Dhaka, ISBN-10: 9280638556, pp: 200.

Taft, C., H. Paul, R. Consunji and T. Miller, 2002. Childhood unintentional injury worldwide: Meeting the challenge. SAFE KIDS Worldwide, Washington (DC). 